\title{
Microstructural Study of Internal Oxidation of Dilute Ni-Al Alloys
}

\author{
O. Hernández-Negrete ${ }^{1}$ and A. Martinez-Villafañe ${ }^{1}$ \\ ${ }^{1 .}$ Centro de Investigación en Materiales Avanzados S.C. (CIMAV), Chihuahua, Chihuahua, México.
}

Internal oxidation occurs when a component of an alloy is selectively oxidized so fast that it can't reach the surface to form an oxide scale. Then it results in a subsurface formation of oxide precipitates that embrittle and expand the alloy subsurface, causing break off and failure of structural components [1]. Particularly, Aluminium depleted $\gamma \mathrm{Ni}$-Al solid solutions are susceptible to internal oxidation $[2,3]$. Most of the research performed on the internal oxidation of dilute NiAl alloys has been done at 1,5 , and $10 \mathrm{~h}$ $[1,2,3]$. Here $20 \mathrm{~h}$ of internal oxidation is presented to complement current research.

NiAl dilute alloys of composition 1.0, 2.5 and 4 wt. \% Al (namely A, B and C respectively) were prepared using pure elements $(\geq 99.9$ wt \% purity) and clean melting with non-consumable tungsten electrode in a copper water-cooled crucible. The cast alloys were heat treated in vacuum at $1200{ }^{\circ} \mathrm{C}$ during $24 \mathrm{~h}$ for homogenization. Electropolishing was used to obtain a clean surface on the samples prior to oxidation. Rhines Pack method [4] at $1100^{\circ} \mathrm{C}$ for 1,10 and 20 hours were used for internal oxidation (isothermal). The cast alloy, heat treated, oxidized and internal oxidation products, were characterized using X-Ray diffraction (XRD), Scanning Electron Microscopy and Energy Dispersive XRay spectroscopy SEM/EDS analyses. For the analysis of exposed internal oxide precipitates, metal from the alloy surface and from the internal oxidation zone (IOZ) was removed with deep electrochemical etching.

BSE images of the cross-section in the alloys after internal oxidation (Figure 1), alloys B and C (2.5 and 4 wt. \% Al respectively) show non-uniform oxidation front; the alloy B presented a lateral discontinuous development of $\mathrm{Al}_{2} \mathrm{O}_{3}$ layer with dark grey contrast at the oxidation front. The alloy $\mathrm{C}$ presented the shortest IOZ including at grain boundaries where the precipitation front was deeper. It also presented a coarse $\mathrm{Al}_{2} \mathrm{O}_{3}$ inner layer which clearly indicated the transition from internal to external oxidation. SE images of the exposed oxide precipitates after deep electrochemical etching and X-Ray elemental maps in figure 2 show morphology and their elemental composition. In alloys $\mathrm{A}$ and $\mathrm{B}$, the precipitates formed as a network of rod-like oxide particles grown from the oxidation front to the alloy surface while in alloy $\mathrm{C}$ rod-like precipitates were attached to a compact $\mathrm{Al}_{2} \mathrm{O}_{3}$ layer formed in the oxidation front. $\mathrm{XRD}$ diffractograms of the alloy $\mathrm{B}$ in all studied conditions shown in figure $3 \mathrm{a}$ suggested the presence of $\mathrm{Ni}_{\mathrm{ss}}$ for cast and heat-treated conditions, $\mathrm{Ni}_{\mathrm{ss}}$ and $\mathrm{NiAl}_{2} \mathrm{O}_{4}$ phase after all internal oxidation times. The insert image in figure $3 \mathrm{a}$ also shows the XRD data of deeply etched $\mathrm{A}, \mathrm{B}$ and $\mathrm{C}$ alloys and suggested the presence of $\mathrm{Ni}_{\mathrm{ss}}$ and $\mathrm{NiAl}_{2} \mathrm{O}_{4}, \alpha-\mathrm{Al}_{2} \mathrm{O}_{3}$ phases. Elemental line scans of a cross-section of the etched alloy $\mathrm{B}$ in figure $3 \mathrm{~b}$ suggests $\mathrm{Al}_{2} \mathrm{O}_{3}$ at the oxidation front and $\mathrm{NiAl}_{2} \mathrm{O}_{4}$ near the surface of the alloy [5].

\section{References:}

[1] F.H Sttot et al, Solid State Ionics 12 (1984), p. 365.

[2] H.M. Hindam and D.P Whittle. Materials Science 18 (1983), p.1389.

[3] D. J. Young in "High Temperature Oxidation and Corrosion of Metals", ed. Tim Burstein, (Elsevier, Oxford), p. 247. 
[4] F.N. Rhines, W. Johnson, W. Anderson. Trans. Am. Inst. Min. Metall. Engrs. 147(1942), p. 205.

[5] O. Hernández-Negrete acknowledges a scholarship provided by CONACyT. This work is dedicated to the memory of professor Alberto Martinez Villafañe.
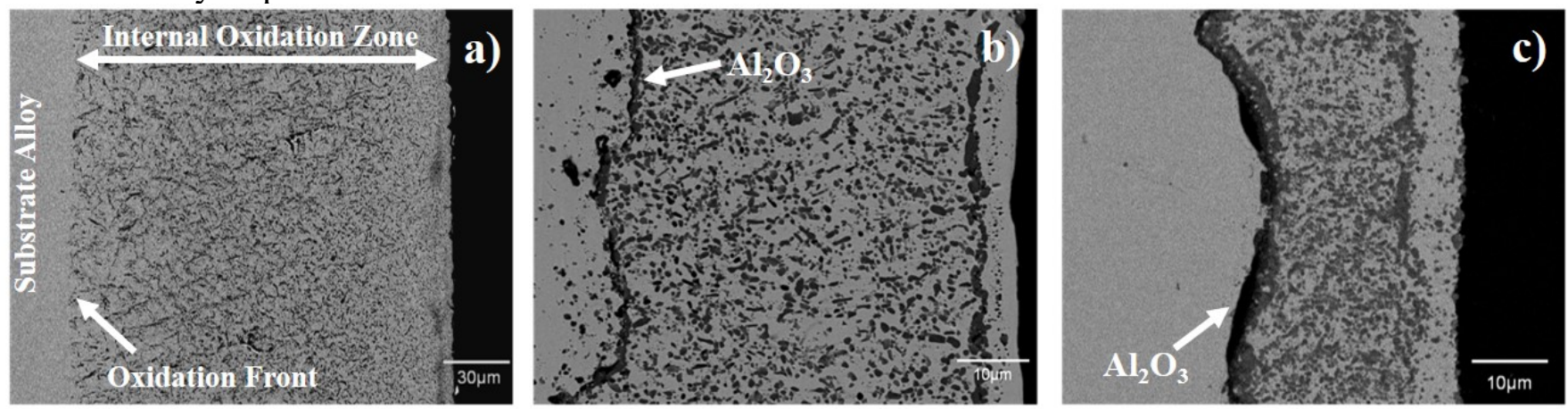

Figure 1. a) BSE images of typical microstructure of the internally oxidised alloys for $20 \mathrm{~h}$ a) $1 \mathrm{wt}$. \% Al, b) 2.5 wt. $\%$ and c) 4 wt. $\%$ Al.
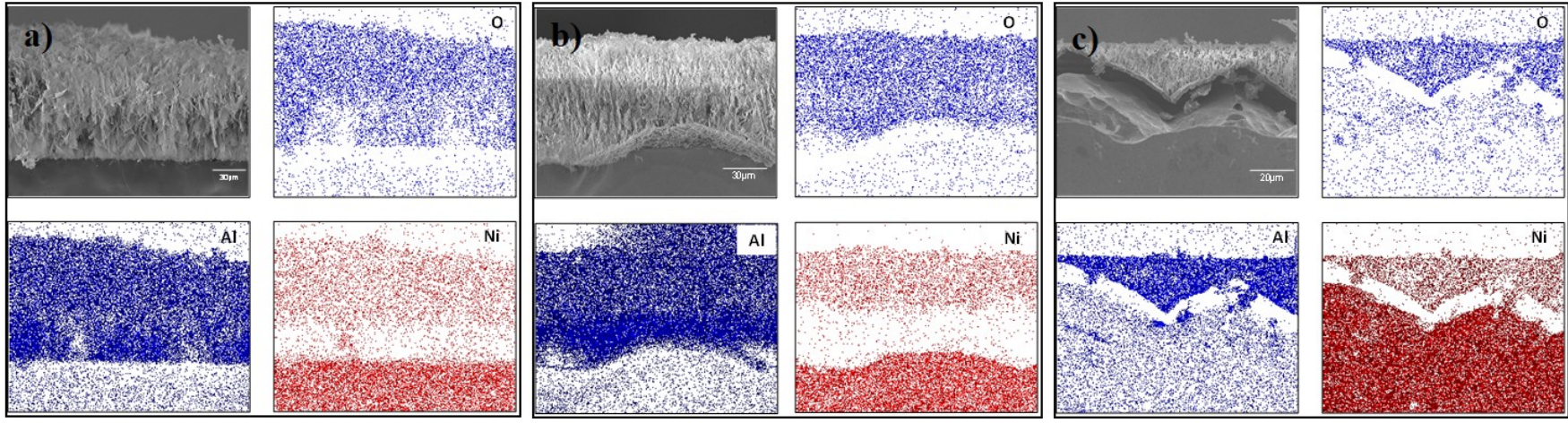

Figure 2. X-ray elemental maps and SE images from cross section of deeply etched alloys after internal oxidation at $1100^{\circ} \mathrm{C}$ for $20 \mathrm{~h}$, a) Alloy A , b) Alloy B and c) Alloy C.
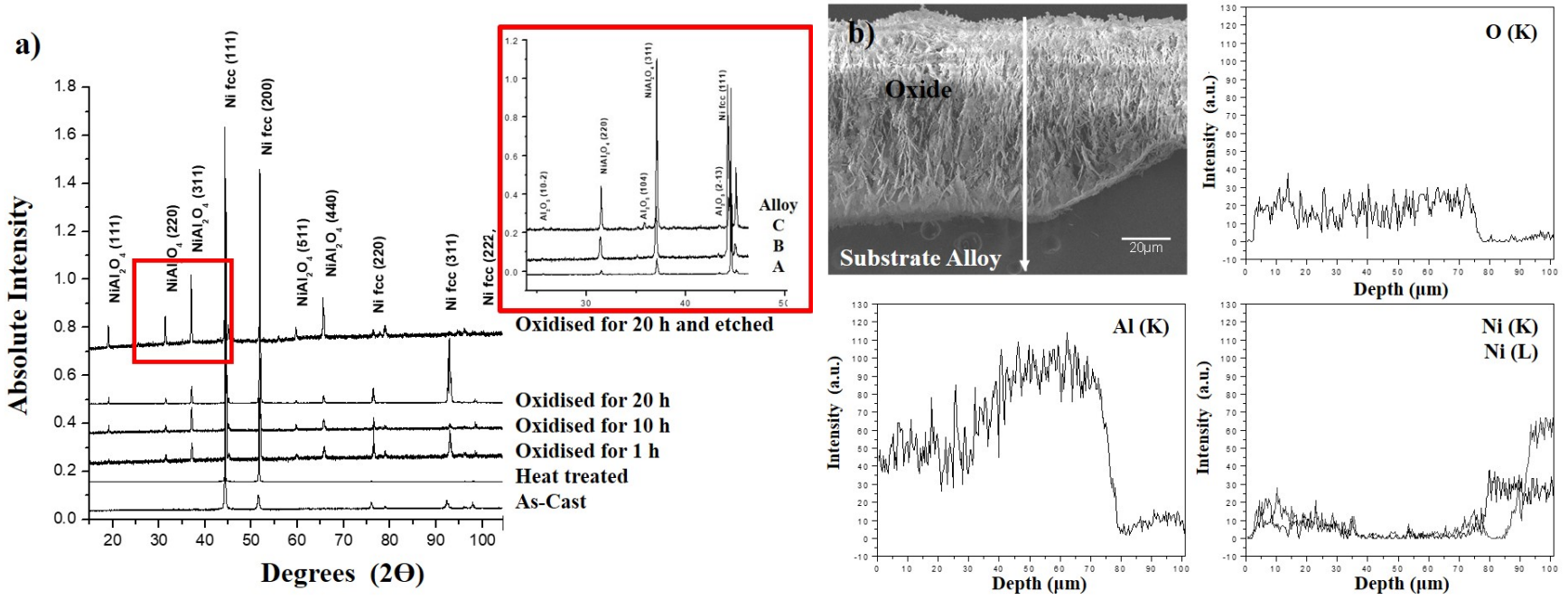

Figure 3. a) XRD diffractograms of the alloy B in the as-cast and heat treated conditions, oxidised for 1, 10 and $20 \mathrm{~h}$ and deeply etched after oxidation for $20 \mathrm{~h}$, insert image show $\mathrm{Al}_{2} \mathrm{O}_{3}$ peaks in the deeply etched alloys after internal oxidation for $20 \mathrm{~h}$, b) Elemental line scans of a cross section of the deeply etched alloy B after internal oxidation at $1100{ }^{\circ} \mathrm{C}$ for $20 \mathrm{~h}$. 